\title{
Percepção de lotação e grau de satisfação dos visitantes da Gruta da Lapinha (Parque Estadual do Sumidouro, MG, Brazil)
}

\section{Crowding perception and satisfaction of visitors at the Lapinha Cave (Sumidouro State Park, Minas Gerais, Brazil)}

Marina Menezes Giusti Bacharel em Turismo pela Universidade Federal de São Carlos Grupo de pesquisas DemandaTur, UFSCar, Brasil marinagiusti93@hotmail.com

Luiz Eduardo Panisset Travassos Doutor em Geografia, professor do Programa de Pós-Graduação em Geografia da PUC Minas Grupo de pesquisas DemandaTur, UFSCar, Brasil luizepanisset@gmail.com

Heros Augusto Santos Lobo Bacharel em Turismo, Doutor em Geociências e Meio Ambiente, Professor da UFSCar Grupo de pesquisas DemandaTur, UFSCar, Brasil heroslobo@hotmail.com

\section{Resumo}

Cavernas são recursos naturais diferenciados que apresentam elevado interesse turístico. As atividades humanas realizadas em cavernas devem ser conduzidas de forma sustentável, respeitando a capacidade de carga do ambiente e, também, a percepção de lotação dos visitantes. Neste contexto, foram pesquisados o perfil do visitante, seu grau de satisfação e sua percepção de lotação na gruta da Lapinha, uma das mais conhecidas cavernas turísticas do Brasil. A pesquisa foi feita com o uso de um questionário, aplicado aos visitantes com o uso de tablets, durante o feriado de Carnaval (08 a 14 de fevereiro de 2018). Mesmo se tratando de um período de alta temporada, os resultados apresentaram altos índices de aprovação do receptivo, dos funcionários, dos monitores e da receptividade local. Dos visitantes entrevistados, 32,3\% indicaram que o grupo estava com quantidade de pessoas superior à desejada, evidenciando o limite atingido na percepção de lotação e levantando questões para a gestão sobre o dimensionamento dos grupos. Ademais, a pesquisa também demonstrou que a população local que não possui vínculo empregatício com o Parque, não está sendo beneficiada diretamente pela atividade turística, visto que a maior parte dos visitantes são excurcionistas e, em sua maioria, não se alimentam ou pernoitam no município.

Palavras-chave: Capacidade de carga; qualidade no turismo; espeleoturismo; cavernas turísticas. 


\begin{abstract}
Caves are differentiated natural resources that present high tourist interest. Human activities carried out in caves must be conducted sustainably, respecting the carrying capacity of the environment and also crowd perception from the visitors. In this context, research was carried out about the profile of the visitor, their degree of satisfaction and their crowd perception in the Lapinha Cave, one of the best-known show caves in Brazil. The survey was conducted using a questionnaire, applied to visitors using tablets, during the Carnival holiday (February 8-14, 2018). Even when it is a high season, the results showed high approval ratings regarding the reception, employees, guides and local hospitality. Of the interviewed visitors, 32.3\% indicated that the group had more people than desired, highlighting the limit reached in the crowding perception and raising questions for the management about the size of the groups. Also, the survey showed that the local population who has no employment relationship with the Park is not directly benefiting from tourism, as most visitors are excursionists and mostly do not eat or stay overnight in the surroundings.
\end{abstract}

Keywords: Carrying capacity; quality in tourism; cave tourism; show caves.

\title{
1. INTRODUÇÃO
}

A realização do turismo em cavernas requer cuidados específicos em função de suas condições naturais diferenciadas. O confinamento espacial limita a dispersão dos impactos da visitação (HEATON, 1986), além da maior fragilidade da fauna que estes ambientes abrigam (TRAJANO; NERI, 2018), sua relativa estabilidade atmosférica (CALAFORRA et al., 2003; LOBO, 2015; TRAVASSOS, 2016) e o fato de serem, muitas vezes, repositórios naturais da vida e das condições ambientais pretéritas na Terra (MACEDO NETO; RIBEIRO, 2018).

O uso de uma caverna para fins turísticos requer a adoção de estratégias de controle da visitação, com enfoques: espacial (BOGGIANI et al., 2007; LOBO, 2009); temporal (LOBO et al., 2013; LOBO, 2015); e comportamental (DOORNE, 2000; BORGES et al., 2013; MASUTTI; LOBO, 2018). Este último objetiva tanto a manutenção da qualidade ambiental quanto a segurança e o conforto dos visitantes. Tais aspectos convergem os esforços de planejamento e gestão para abordagens de capacidade de carga turística cujo foco de abordagem se desconcentra dos números de visitas diárias e converge para a dinâmica e os padrões de visitação - tal como preconizado nos trabalhos de McCool e Lime (2001); Lobo et al. (2013) e Guirado et al. (2014).

Assim, com base nestes pressupostos teóricos e metodológicos, a seguinte questão-problema de pesquisa foi proposta: pode a percepção de lotação dos visitantes influenciar em sua experiência de visitação e contribuir para a delimitação da capacidade de carga turística? Para buscar investigar a questão, realizou-se uma pesquisa na gruta da Lapinha, localizada no Parque Estadual do Sumidouro, em Lagoa Santa-MG. A gestão da UC é feita pelo pode público, por meio do Instituto Estadual de Florestas 
(IEF). Trata-se de uma das três mais tradicionais cavernas turísticas do Estado de MG, recebendo milhares de visitantes anuais. A gruta da Lapinha é iluminada artificialmente e possui diversas facilidades e infra-estruturas de visitação. Por outro lado, seu espaço interior é relativamente restrito, gerando gargalos no processo de visitação e pontos onde a percepção de lotação pode ser aguçada, pela proximidade das paredes e teto, configurando-se em situação de relativo confinamento quando comparada com outras cavernas turísticas. Neste cenário, a pesquisa desenvolvida teve o objetivo de verificar a percepção de lotação dos visitantes e suas possíveis consequências na avaliação de qualidade do roteiro de visitação na gruta da Lapinha.

\section{PROCEDIMENTOS METODOLÓGICOS}

\subsection{Caracterização da área de pesquisa}

A gruta da Lapinha está localizada na porção sudoeste do Parque Estadual do Sumidouro (PESU) - região do Planalto dos Dolinas (IEF; GHEOSFERA, 2010). Descoberta em 1835 por Peter W. Lund, somente em 1965 foi aberta para visitação. A caverna possui cerca de $630 \mathrm{~m}$ de extensão horizontal, com várias galerias que interligam seus diversos salões (IEF; GHEOSFERA, 2010) e um circuito linear de visitação (fig. 1). Historicamente, a caverna recebe aproximadamente 20.000 vistantes anuais, nos últimos dez anos. A visitação da Lapinha é feita de terça a domingo, das 8h30 às 16h (última entrada), com permanência até às 17h. A visitação é feita em grupos compostos por até 20 visitantes, obrigatoriamente acompanhados de um monitor local, com intervalos de 20 a 30 minutos entre eles, totalizando um máximo de 24 grupos/dia. O trajeto se inicia no receptivo da gruta em seu lado externo, no qual são feitas explicações sobre as características ambientais e sociais ligadas à região de Lagoa Santa e à caverna (fig. 2a). Em seguida, o grupo se dirije para a gruta (fig. 2b), para a realização de um roteiro de aproximadamente 40 minutos de duração (IEF, 2019). 


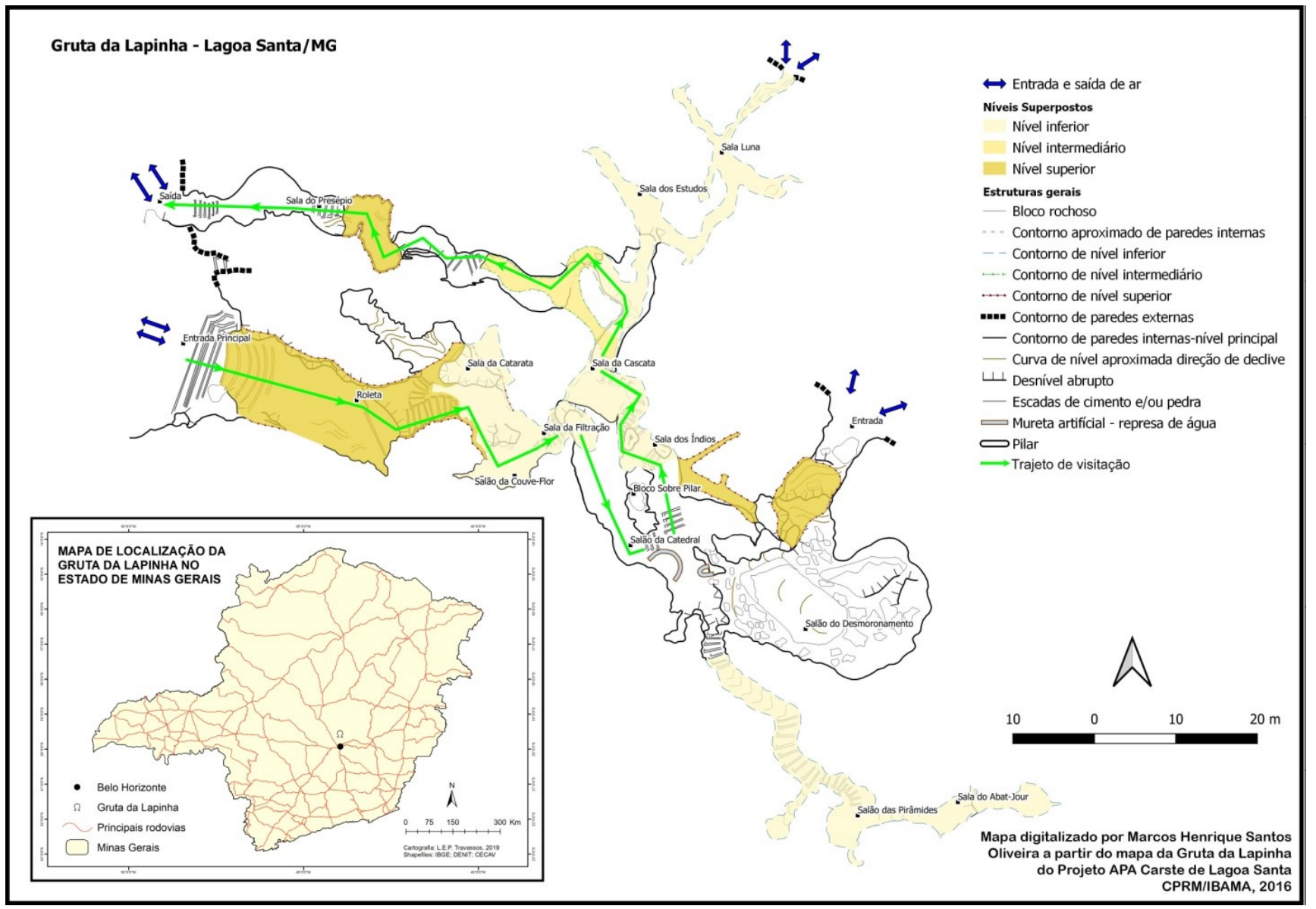

Figura 1. Localização da gruta da Lapinha no estado de Minas Gerais e sua respectiva planta baixa
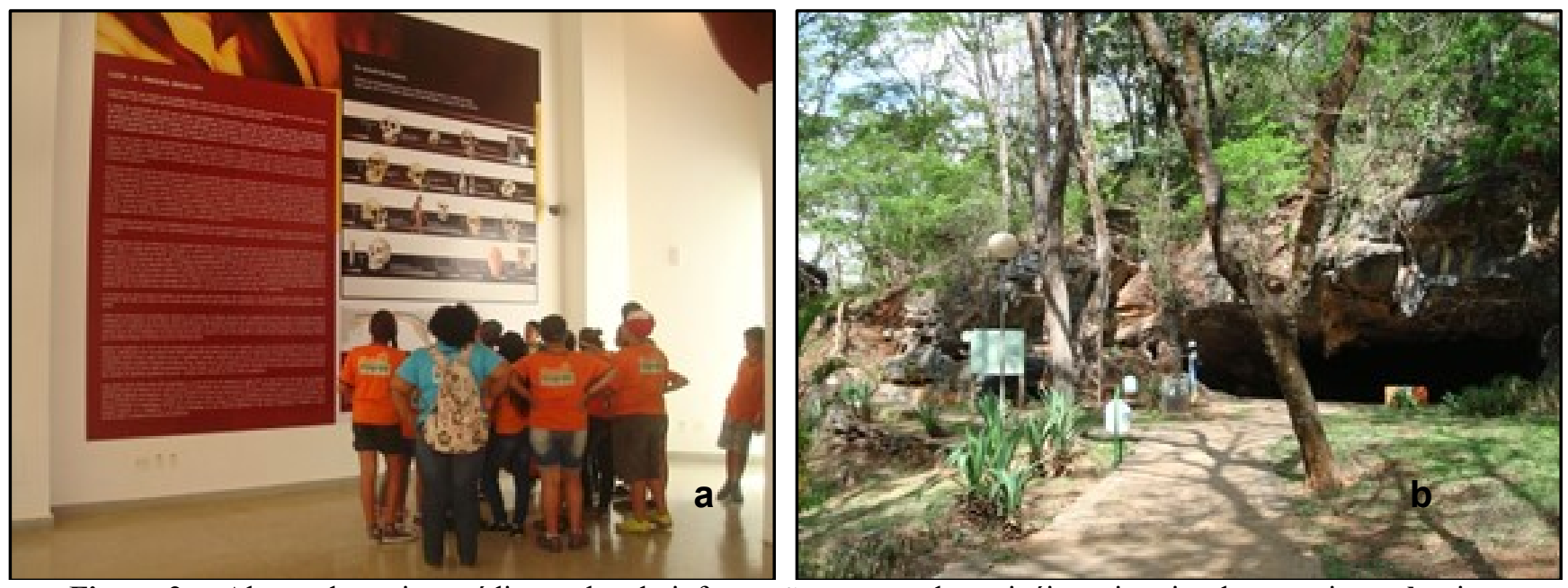

Figura 2a.: Alunos do ensino médio recebendo informações em um dos painéis no interior do receptivo; e b: vista panorâmica da entrada da gruta da Lapinha. 


\subsection{Elaboração e aplicação do instrumento de pesquisa}

A elaboração do instrumento de coleta de dados partiu de questionários elaborados em pesquisas de mesma natureza anteriormente executadas no Parque Estadual Turístico do Alto Ribeira (PETAR), Estado de São Paulo (ALVES, 2016) e na gruta do Lago Azul (MASUTTI; LOBO, 2018), Estado de Mato Grosso do Sul. Foram feitas consultas à gestão do PESU, de forma que esta pudesse contribuir na adaptação do questionário anterior para a realidade local e fizesse apontamentos que contribuíssem para o refinamento da coleta de dados, com base em sua experiência no uso público da caverna. Após pequenos ajustes e testes de campo, a versão final foi adicionada em 3 tablets com o software livre Survey on Tablet para a pesquisa de campo, facilitando a interface de coleta de dados com os visitantes.

A aplicação do questionário ocorreu durante o feriado prolongado de Carnaval, entre os dias 08 e 14 de fevereiro de 2018. Como o objetivo estava ligado à percepção de lotação, entendeu-se ser importante que a aplicação fosse feita em condições de maior volume de visitantes, de forma a captar as percepções em situação de possível desconforto pelo número maior de visitantes simultâneos no roteiro. Neste período foram registrados 631 visitantes à gruta da Lapinha. Destes, 167 turistas foram entrevistados $(27 \%)$. As entrevistas foram realizadas na praça da gruta, local utilizado para lazer e descanso e de passagem obrigatória dos visitantes por dar acesso à saída ao estacionamento do parque.

\subsection{Tabulação dos Dados}

A tabulação de dados foi realizada com o apoio do software livre LibriOffice Calc em ambiente Windows. O software livre Survey on Tablet disponibiliza ao final da captação das respostas a tabulação ordenada de acordo com a sequência de perguntas pré-estabelecidas durante a montagem do questionário. Após o término de aplicação e tabulação via software do questionário, foram elaborados gráficos a fim de facilitar a análise descritiva dos dados obtidos.

\section{RESULTADOS E DISCUSSÃO}

\subsection{Perfil e motivação dos visitantes entrevistados}

Dos 167 entrevistados, 58\% eram do sexo feminino e 42\% masculino. Sobre a escolaridade, $37 \%$ tinham pós-graduação, $34 \%$ o ensino superior completo, $25 \%$ ensino médio completo, $4 \%$ fundamental completo e $2 \%$ tinham fundamental incompleto ou não tinham escolaridade. Este resultado demonstra que o público de visitantes é variado, mas composto por uma maioria com alto grau de escolaridade, com 
$71 \%$ dos entrevistados possuindo, no mínimo, o ensino superior completo. Em se tratando de uma pesquisa em área natural, com um perfil tendendo ao ecoturismo, buscou-se compreender os hábitos dos entrevistados tanto em suas rotinas diárias (fig. 3) quanto relativas às viagens.

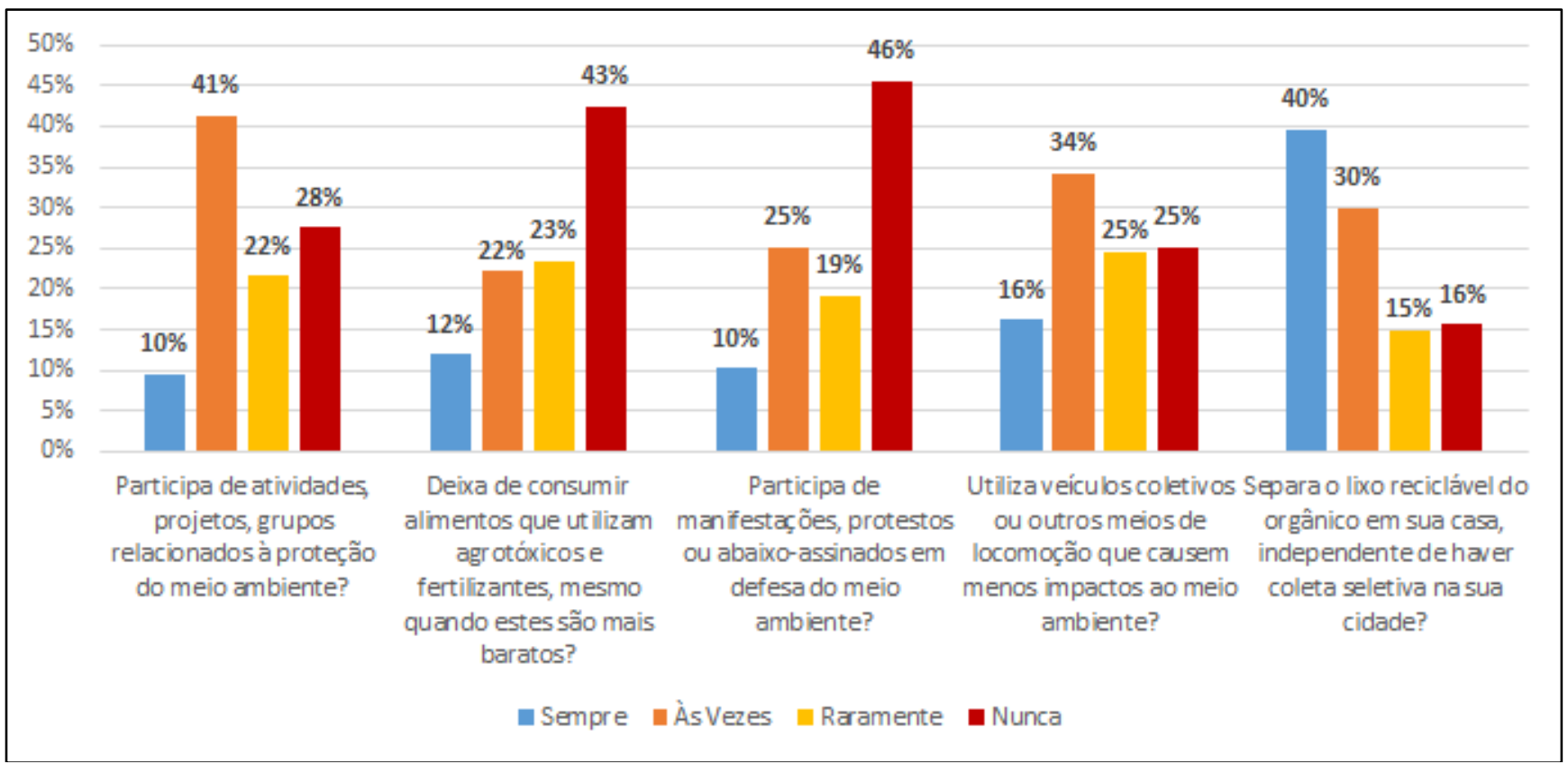

Figura 3. Hábitos cotidianos dos entrevistados relacionados ao meio ambiente

Observa-se que mesmo de forma não frequente (opções "sempre" e "às vezes"), no geral o índice de respostas positivas para os hábitos cotidianos relativos à preocupação com temas ambientais foi representativo, dado que os entrevistados declaram possuir atitudes que contribuem com o meio ambiente. O destaque maior ficou para a separação do lixo reciclável ( $40 \%$ sempre; $30 \%$ às vezes), seguido de perto pela utilização de veículos menos impactantes $(16 \% ; 34 \%)$ e participação em projetos e atividades $(10 \%$; 41\%). Estes dados confirmam pesquisas anteriores feitas em outros contextos localizacionais no Brasil, nos quais se observou tanto a dificuldade no engajamento em atitudes ambientais, como a separação do lixo (FEITOSA et al., 2016) quanto a adoção de práticas mais simples e que interferem menos nos hábitos e no custo de vida (AFONSO et al., 2016).

Quanto ao perfil de grupo da viagem realizada, 45,5\% estavam em um grupo familiar, 16,8\% entre amigos, 16,2\% eram casais sem filhos e 15,6\% eram casais com filhos. O motivo principal da viagem foi lazer (97\%) sem a realização de pernoite nas imediações da gruta $(70,7 \%)$. Visitar cavernas não era novidade para a maioria dos entrevistados, pois apenas $27,5 \%$ dos entrevistados estavam indo pela primeira vez em uma caverna.

A motivação do deslocamento que incluiu a visita à gruta da Lapinha foi aferida por meio de 
questões de múltipla escolha em uma escala que variava entre muito importante (nota 5) e nada importante (nota 1). As motivações com maior grau de significado foram a possibilidade de conhecer um novo lugar (muito importante para $77 \%$ dos entrevistados), a vegetação e paisagem do lugar (68\%), o contato com a natureza (67\%) e a possibilidade de aproveitar o tempo com os amigos ou familiares (54\%). A realização de uma atividade de aventura foi assinalada como relevante apenas por 35\% dos respondentes - valor próximo ao dos visitantes que nunca tinha ido a uma caverna antes. Este resultado evedencia tanto um provável conhecimento prévio de grande parte dos respondentes sobre o baixo grau de dificuldade da visitação da gruta Lapinha quanto o risco de generalização ao compreender o espeleoturismo apenas como uma atividade de aventura (cf. LOBO et al., 2010). Ainda no âmbito das motivações, $84 \%$ dos respondentes informaram que o principal atrativo que influnciou a realização da visita foi a caverna propriamente dita, em detrimento de opções como a cultural local (39\%), cachoeiras (27\%) e visualização de animais (23\%). Motivações como "cachoeiras" e "visualizações de animais" podem ser explicadas pelo fato da gruta da Lapinha estar relativmente próxima da Serra do Cipó, local onde tais atributos exercem atratividade na visitação. Com isso, associado ao fato da maioria não estar pernoitando nas imediações, deduz-se a possibilidade da Lapinha ser uma rota de passagem para turistas indo ou vindo da região do Cipó.

\subsection{Percepção de lotação}

A avaliação da percepção de lotação é um componente da capacidade de carga social (DOORNE, 2000), na qual se observa se os limites propostos para a visitação, em termos de dimensionamento dos grupos, frequência e duração da visitação, interferem na qualidade da experiência vivenciada (ALEGRE; GARAU, 2010; CAMPO-MARTÍNEZ; GARAU-VADELL, 2010; MANNING; HALLO, 2010).

Em relação ao tamanho dos grupos, embora o limite máximo de pessoas por grupo na gruta da Lapinha seja de 20 visitantes, observou-se na prática que exceções eram realizadas, em função da ausência de agendamento prévio dos visitantes, o que gerava a necessidade de ajustes para acomodar demandas de grupos pré-existentes de familiares ou amigos. Por outro lado, muitos grupos visitaram a gruta abaixo do limite máximo, em função de não completar o grupo em um curto intervalo de tempo. Este aspecto foi observado por $61,1 \%$ dos respondentes, com grupos que variavam entre 2 e 19 pessoas (fig. 4). 


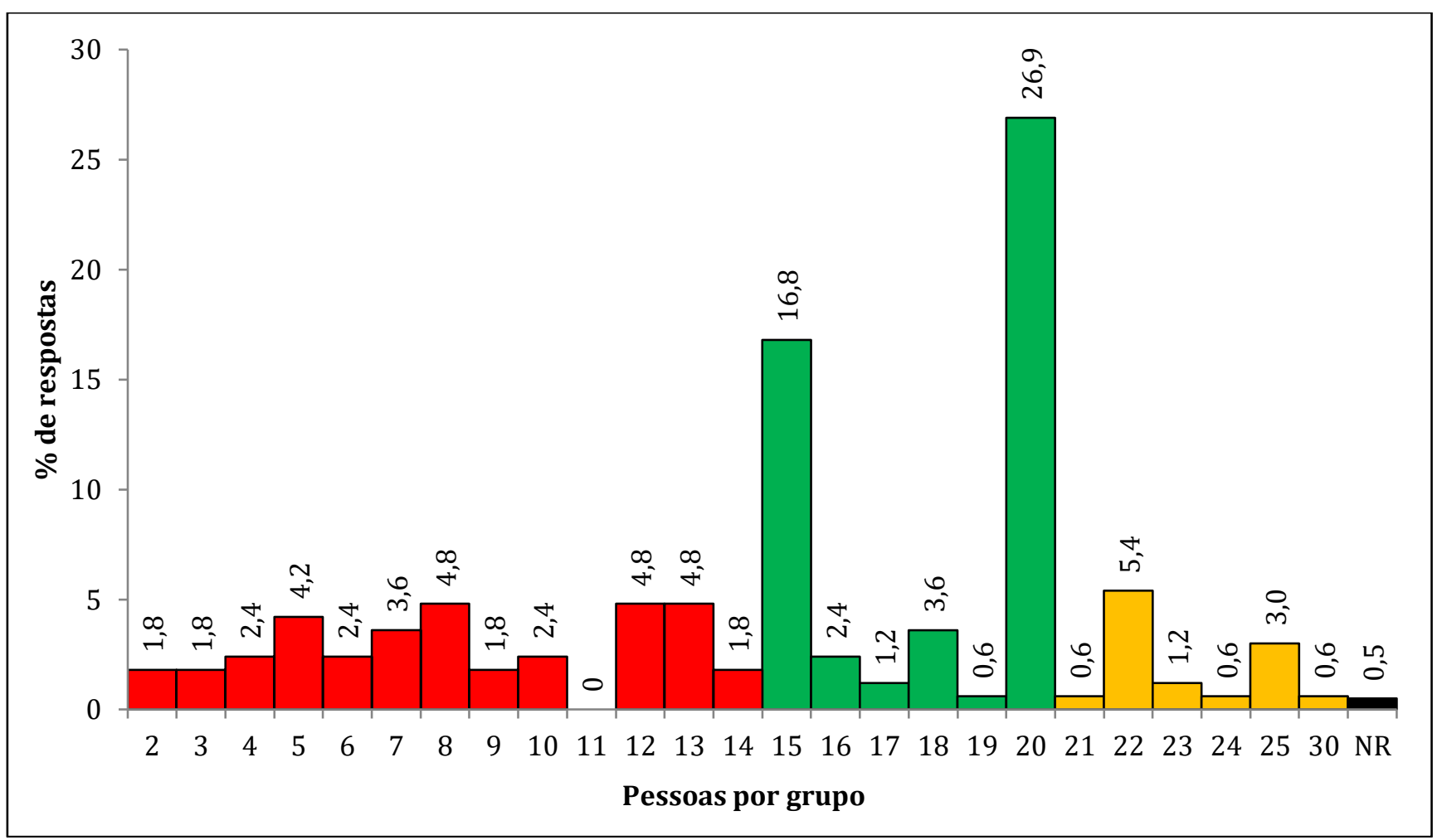

Figura 4. Percepção do número de pessoas que estavam no grupo. Vermelho: grupos muito abaixo do limite de pessoas por grupo; Verde: grupos dentro do limite e com melhor aproveitamento da capacidade de atendimento; Laranja: grupos acima do limite; Preto: não responderam.

Do total de entrevistados, $88,1 \%$ disseram estar em grupos com quantidade de pessoas dentro do limite estabelecido pelo PESU, de 20 visitantes por grupo, sendo que uma parcela significativa $(36,6 \%)$ estava em grupos subdimensionados - abaixo de 15 visitantes por grupo. O restante dos visitantes $(11,9 \%)$ afirmou estar em grupos com totais de visitantes acima do limite regular (entre 21 e 30 visitantes por grupo).

A visitação em grupos com totais de visitantes em quantidades muito diferentes da estipulada pela gestão deve ser observada sob dois enfoques. Primeiro, os dados evidenciam o baixo aproveitamento relativo do serviço de visitação ofertado, com 36,6\% dos visitantes em grupos abaixo de 15 pessoas. Com isto, há uma sobreoferta de serviços em função da demanda, deixando os envolvidos no processo de visitação parcialmente ociosos, mesmo em períodos de alta temporada, como a época pesquisada. O outro aspecto evidenciado é sobre os grupos que operaram acima do limite estipulado de visitantes. Deve-se observar com detalhe se estas situações não interferem negativamente na percepção de lotação do ambiente e, por consequência, na qualidade da experiência de visitação. Para isso, buscou-se comparar os dados da classificação geral dos tamanhos de grupos pelos visitantes (fig. 5a) com a classificação dos tamanhos de grupos dadas pelos respondentes de grupos acima do limite usual (fig. 5b). 
a

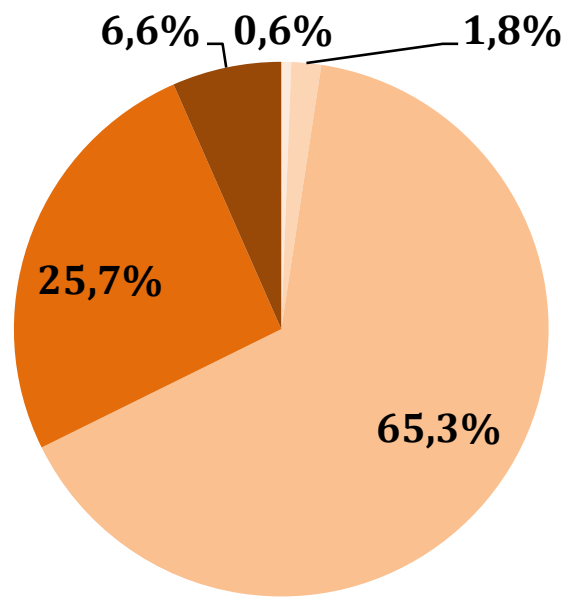

Muito pequeno

Adequado

Muito grande
Um pouco pequeno

Um pouco grande $\mathrm{b}$

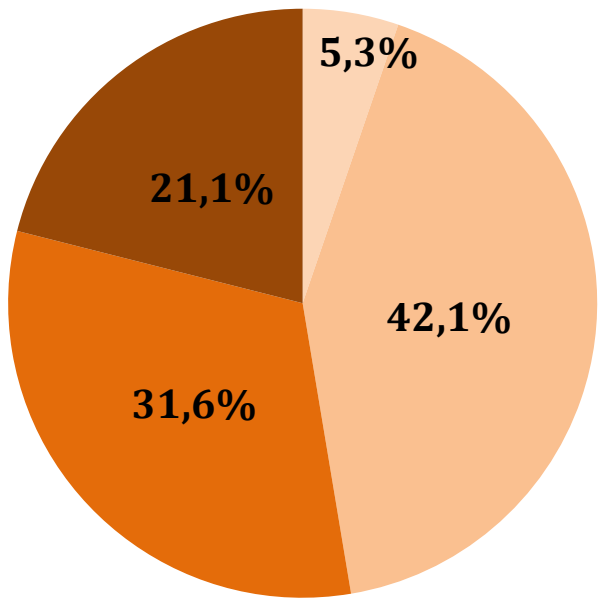

Um pouco pequeno

Adequado

- Um pouco grande $\quad$ Muito grande

Figura 5. Classificação de tamanho dos grupos pelo total de visitantes (a) e pelos visitantes de grupos acima do limite de visitação estipulado (b)

Conforme ilustrado na fig. 5, a maior parte dos entrevistados (65,3\%) classificou o seu grupo de visitação como sendo de um tamanho adequado. No geral, o índice de reprovação por excesso de visitantes foi moderado, com 25,7\% dos visitantes julgando seu grupo como um pouco grande e 6,6\% julgando o grupo como muito grande. Em detalhe, ao se analisar apenas as opiniões dos visitantes que estavam em grupos com mais de 20 visitantes (fig. 5b), observa-se que o julgamento pela adequação do tamanho do grupo cai para $42,1 \%$ e que as avalições para grupos considerados um pouco grandes $(31,6 \%)$ e muito grandes $(21,1 \%)$ sobem substancialmente. Considerando que a quantidade de pessoas por grupo é definida por questões de disponibilidade espacial das áreas de parada ou mesmo do alcance de atendimento do condutor responsável (Cifuentes, 1992), ou mesmo de forma intuitiva e empírica (Lobo et al., 2013), é preciso observar a necessidade de ajuste deste importante parâmetro da visitação.

$\mathrm{Na}$ continuidade, buscou-se observar a totalidade dos visitantes que consideraram os seus respectivos grupos como sendo inadequados por serem um pouco ou muito grandes (fig. 6). O objetivo foi verificar o tamanho do grupo em que estavam, de forma a identificar eventuais problemas nos diversos padrões aleatórios de visitação gerados pelo controle da visitação no período analisado. 


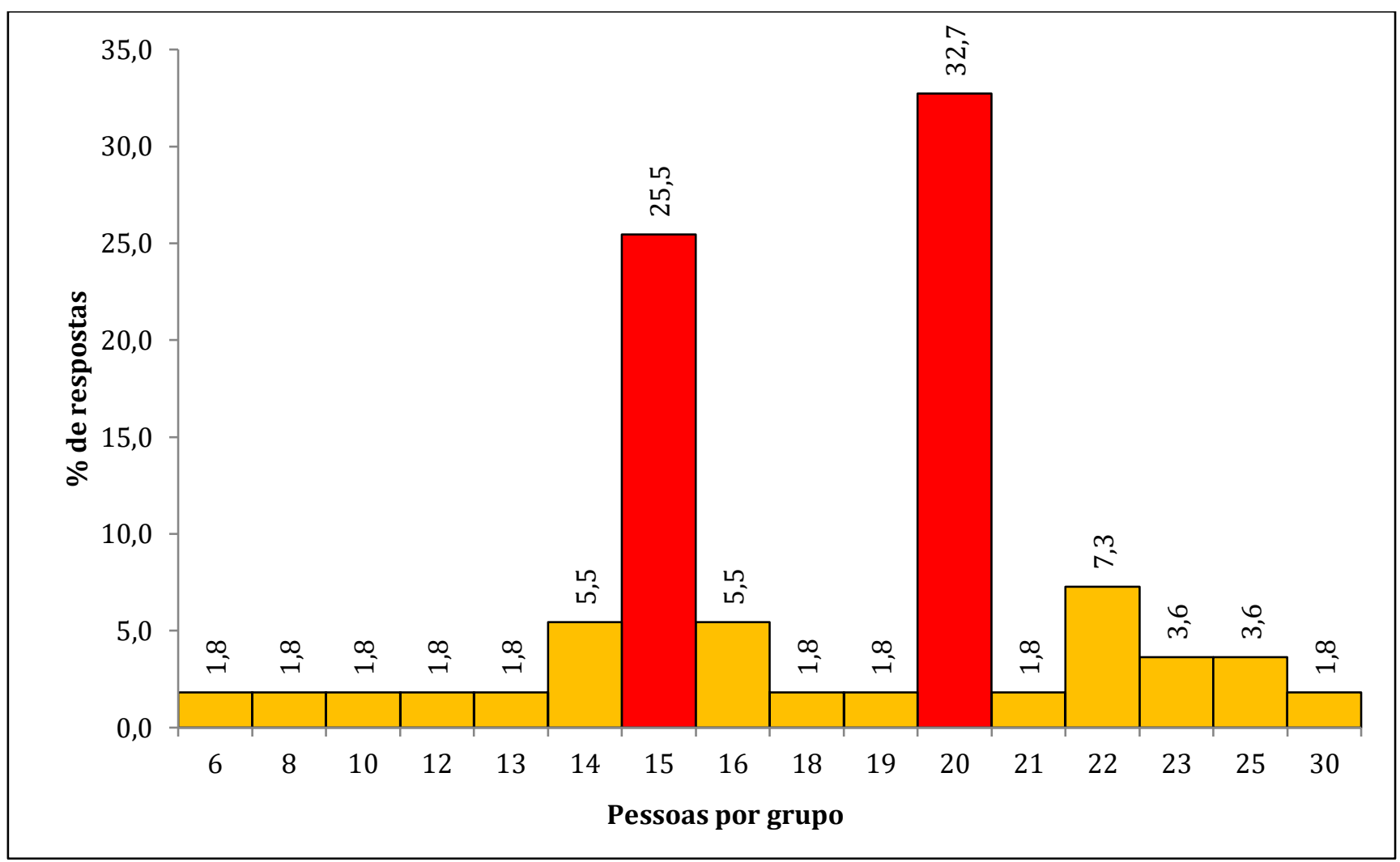

Figura 6. Percepção do número de pessoas que estavam nos grupos avaliados como "um pouco" ou "muito" grandes pelos visitantes (em vermelho, os tamanhos de grupos que tiveram maior destaque negativo)

A análise da totalidade da amostra de pessoas que consideraram os seus respectivos grupos como sendo "grandes" (fig. 6) apresenta resultados que permitem relativizar a percepção de lotação (cf. DOORNE, 2000) de cada indivíduo. Mesmo em grupos menores, de até 10 pessoas, esta observação foi realizada - o que pode se explicar tanto pela expectativa dos visitantes - que por vezes, espera menores aglomerações de visitantes em áreas naturais (McCOOL; LIME, 2001) - quanto pela possível distorção gerada pelo confinamento espacial, a qual é bastante evidente na gruta da Lapinha. No entanto, os tamanhos de grupos que tiveram maior percentual de observações de incorformidade em função de serem maiores que o esperado foram os de 20 pessoas $(32,7 \%)$ e de 15 pessoas $(25,5 \%)$. Este aspecto é casuístico em relação ao tamanho específico de grupos apontados e está ligado ao fato de que a maior parte dos grupos que visitaram a caverna era composta por grupos de 15 e 20 pessoas (fig. 4). Assim, cruzando os dados das figuras 4 e 6, observa-se que a percepção de lotação não se evidencia diretamente pelo tamanho dos grupos. É provável que aspectos subjetivos de ordem pessoal interfiram neste parâmetro, de modo que não foi possível identificar os motivos que levaram aos resultados obtidos.

\subsection{Satisfação com o roteiro visitado}


A análise da satisfação com a experiência vivenciada no roteiro de visitação da gruta da Lapinha levou em conta os seguintes aspectos: sistema de reserva para a visitação, tempo de espera antes de iniciar o roteiro, tempo de visitação, paradas interpretativas, segurança e aspectos relativos à hospitalidade e serviços recebidos.

A reserva para fazer a visitação na gruta da Lapinha apresentou uma elevada taxa positiva de confirmação, com 91\% dos visitantes conseguindo realizar a reserva para o dia e período (manhã ou tarde) que desejavam. Quanto aos demais, 6,6\% fez a visita em um pacote de agência que incluía a visita à gruta - ou seja, não controlaram o processo de reserva - e apenas $2,4 \%$ afirmaram ter problemas para realizar a reserva. Os problemas citados versavam sobre a indisponibilidade de executar roteiros que estavam incluídos no preço do ingresso, por falta de informação e por falta de pessoal no receptivo em função de um feriado prolongado. Portanto, mesmo com o alto índice de respostas positivas, deve-se atentar às respostas negativas, já que elas evidenciam pequenas falhas na execução dos serviços de uso público em dias de maior movimento. Ainda em relação aos aspectos prévios à visitação, foi também perguntado sobre a percepção do tempo de espera para iniciar o roteiro (fig.7). Isto porque o agendamento da visitação não é feito com horário exato tal como em outras cavernas turísticas (e.g. gruta do Lago Azul, em Bonito-MS). Dependendo do volume de visitantes esperados para um determinado dia ou período, pode haver um maior tempo de espera, pois há um intervalo de entrada entre os grupos que é de aproximadamente 30 minutos e, também, pode haver indisponibilidade momentânea de guias disponíveis.

A maior parte dos entrevistados $(73,8 \%)$ esperou menos de 30 minutos para o início do roteiro. Destaca-se, no entanto, a menção de $9,6 \%$ dos entrevistados que disseram ter esperado mais de 50 min. para iniciar a visitação, chegando a ser citado um tempo de 1h30min de espera. Estas esperas maiores ocorreram em função da ausência de agendamento, dado que alguns grupos chegavam em horários de pico e tinham que esperar mai tempo para iniciar o roteiro, em função do respeito ao intervalo de 30 minutos entre os grupos. Os resultados agrupados como "outros" são correspondentes a respostas qualitativas, como "pouco tempo", o que não permitiu aferir em escala absoluta. Também foi perguntado se este tempo de espera era adequado. No geral, o tempo de espera vivenciado foi considerado aceitável para $75,5 \%$ dos visitantes - valor muito próximo do total de entrevistados que esperaram menos de 30 minutos. Assim, entende-se que tal intervalo de espera não é negativo para a experiência de visitação, mas deve-se tomar cuidado com os intervalos maiores. 


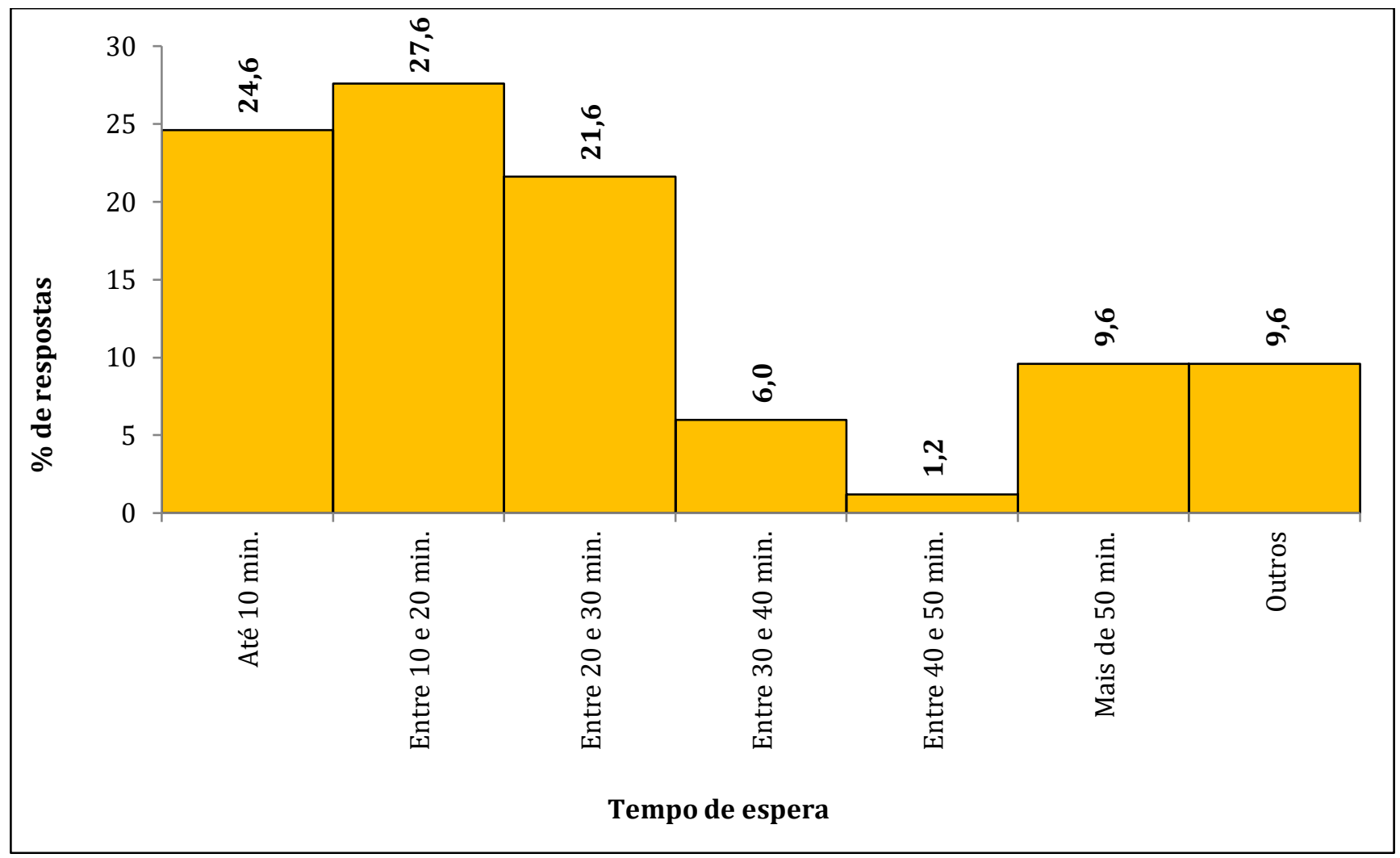

Figura 7. Percepção de tempo de espera desde a chegada de visitante até o início da visita

Na continuidade foi feita a avaliação do roteiro de visitação dentro da gruta da Lapinha, iniciando com o tempo de duração. Oficialmente, a vistação da gruta da Lapinha leva em torno de 40 min. No entanto, é sabido que o ambiente subterrâneo altera a percepção temporal das pessoas, em função da ausência de referência luminosa (BARRIONUEVO et al., 2019). A este fator se alia o fato de que os visitantes estão, em sua maioria, em seu tempo livre e desprendidos da rotina diária de compromissos, o que também contribui para sua perda da noção de tempo (GRABURN, 2001). Os resultados sobre a percepção de tempo de duração do roteiro e da avaliação dos visitantes sobre este tempo são apresentados na fig. 8 .

Em relação ao tempo de permanência (Fig. 8 - esquerda), 60,5\% dos entrevistados disse que permaneceu entre 30 e 40 minutos dentro da caverna, 25\% disse que ficaram menos de 30 minutos e 15\% afirmaram que permaneceram mais de 40 minutos. Quanto a classificação deste tempo (Fig. 8 - direita), $81,4 \%$ consideraram adequado e 15,6\% consideraram um pouco curto. As demais opções de avaliação tiveram pouca significância estatística. Com estes resultados observa-se que mesmo havendo uma variação significativa da percepção de tempo de permanência de um entrevistado para outro, no geral, a classificação atribuída ao tempo de visitação permaneceu positiva. 


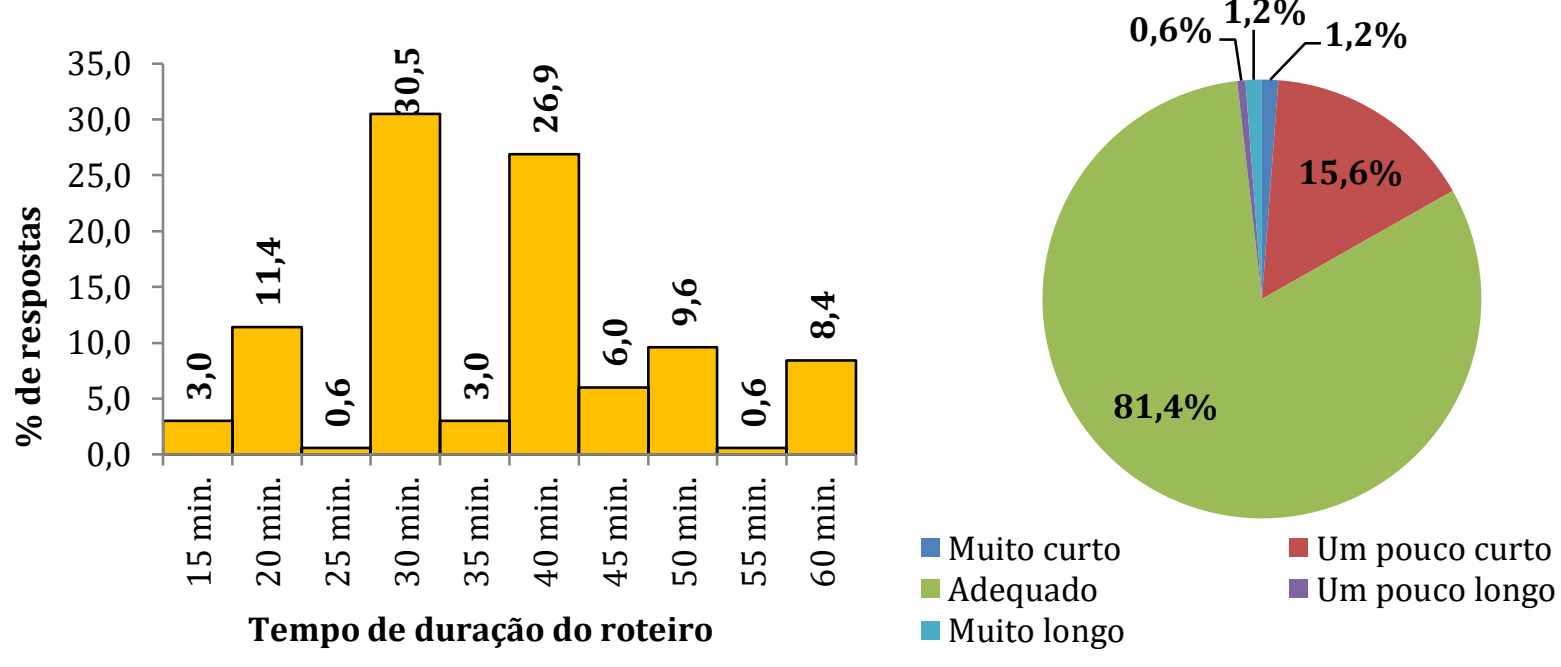

Figura 8. Percepção da permanência dentro da gruta (esquerda) e classificação deste tempo pelo visitante (direita)

Outro ponto focado sobre o roteiro de visitação foram as paradas interpretativas. Estas são importantes para o processo de visitação, pois permitem que os guias possam informar ao visitante a importância do local, apresentar a história, a formação da gruta e fatos interessantes, além de permitir ao visitante uma aproximação maior com o local. Permitem também o desenvolvimento de atividades de educação ambiental e o aproveitamento das características diferenciadas do ambiente subterrâneo em atividades conduzidas pelos guias. Na gruta da Lapinha, foi perguntado ao visitante sobre sua satisfação com a quantidade, duração e conforto nas paradas interpretativas (fig. 9).
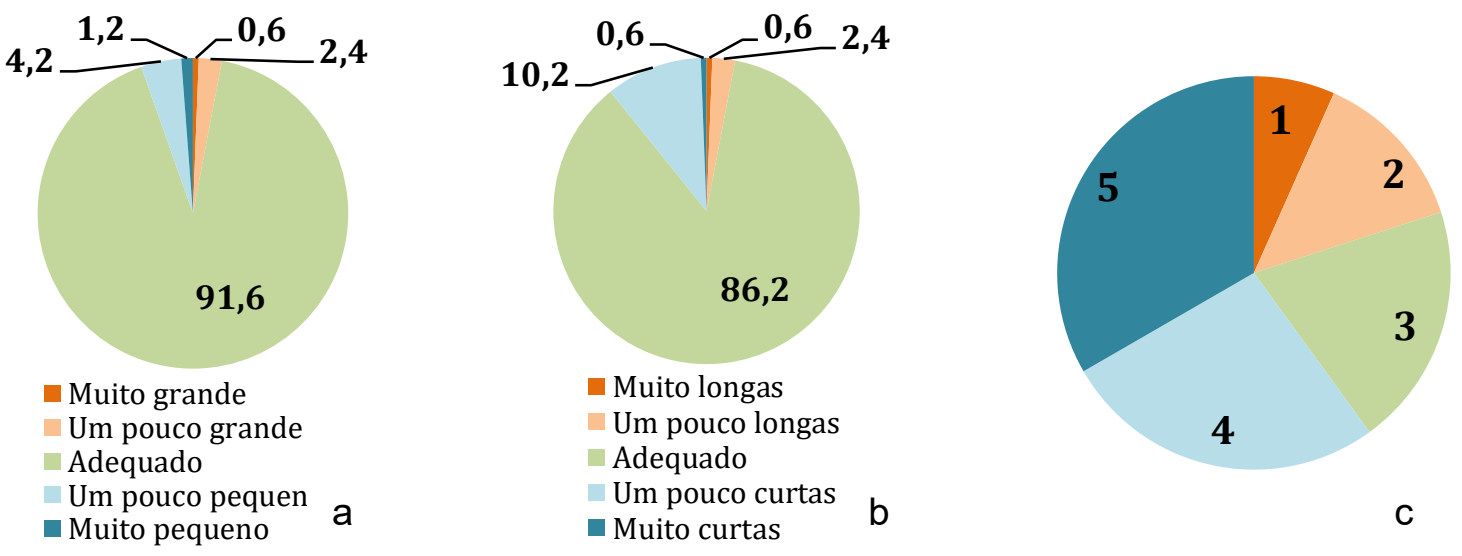

Figura 9. Percepção de satisfação dos visitantes sobre a quantidade de paradas interpretativas (a), seu tempo de duração (b) e sensação de conforto (c) 
No caso da gruta da Lapinha, nota-se que a maioria dos aspectos analisados recebeu avaliações predominantemente positivas, com destaque para a quantidade de paradas (fig. 9a) - adequadas para $91,6 \%$ dos entrevistados - e seu tempo de duração (fig. 9b) - adequado para 86,2\% da amostra. O conforto (fig. 9c) foi avaliado em uma escala entre 1 (mínimo) e 5 (máximo), recebendo notas predominantemente positivas para $84,4 \%$ dos respondentes (43,1\% atribuíram a nota máxima). Incidem sobre a questão do conforto na visitação das cavernas aspectos como a sensação térmica, iluminação e infraestrutura de visitação, entre outros de caráter mais individual (CIGNA; BURRI, 2000). É importante frisar que a gruta da Lapinha possui muitas infraestruturas de acesso, como escadarias, corrimãos e iluminação, o que permite que a visitação aconteça sem a necessidade de lanternas individuais e sem grandes dificuldades. Entende-se que tais aspectos contribuem para as avaliações positivas recebidas em relação ao conforto das paradas. Entretanto, foi observado que, embora as regras de visitação indiquem a obrigatoriedade do uso de calçado fechado para segurança do visitante (IEF, 2019), na prática é permitido o acesso de visitantes sem este item, o que aumenta o risco de acidentes como torções de tornozelo.

Por fim, dos aspectos inerentes ao roteiro, também foi questionado sobre a segurança, com foco na percepção de segurança das infraestruturas de acesso dentro da gruta e, também, da possível interferência estética destas na experiência de visitação. A gruta da Lapinha possui infrestruturas pesadas (fig. 10a), desenvolvidas para cavernas com visitação em larga escala, mas que não foram projetadas de forma totalmente integrada à paisagem subterrânea. De igual modo, o sistema de iluminação, embora siga algumas diretrizes de boas práticas para o turismo em cavernas (CIGNA; FORTI, 2013) por ser baseado em LEDs e setorizado, por outro lado, distorce a realidade do ambiente pelo uso de diversas cores na iluminação (fig. 10b).

A escala utilizada para a análise da infraestrutura variou entre 1 e 5, sendo 1 totalmente inseguro e 5 totalmente seguro (para segurança); e 1 representando nenhuma interferência e 5 representando extrema interferência (interferência estética da infraestrutura). Os resultados são ilustrados na fig. 11. 


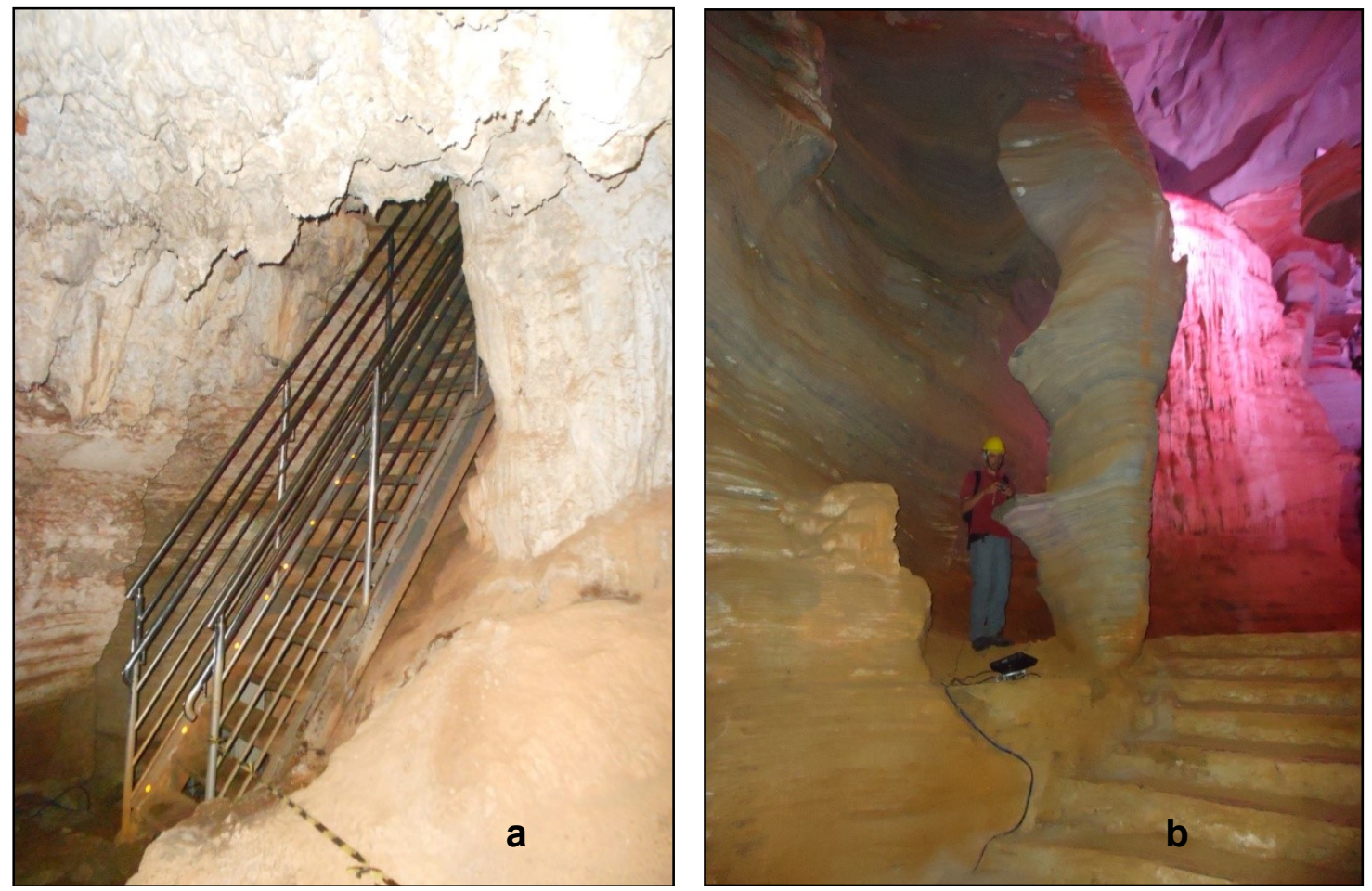

Figura 10a.: escada metálica ilustrando o padrão de infraestrutura de visitação; e b: iluminação artificial com luzes coloridas na gruta da Lapinha.

Em cavernas para a execução do turismo de larga escala, entende-se a necessidade de instalação de infraestruturas mais robustas, tanto para segurança dos turistas quanto do ambiente (CIGNA; BURRI, 2013). Na gruta da Lapinha, sob a ótica da segurança, os resultados evidenciam que as infraestruturas internas atendem ao esperado: não houve menções nas alternativas que indicam insegurança (fig.11a, opções 1 e 2 da escala com resultado $=0$ ) e, por outro lado, uma maioria indicando se sentir seguro (56,3\% na opção 5; 37,7\% na opção 4 e 6\% na opção 3, que corresponde ao neutro da escala). Desconsiderando o neutro, restam ainda $94 \%$ de respondentes se sentido seguros em relação à infraestrutura existente. Esta mesma percepção predominantemente positiva não ocorre em relação à interferência estética das infraestruturas (fig. 11b). Neste caso, 30\% dos respondentes assinalaram as opções 1 e 2 - relativas à menor interferência estética -, 30,5\% mantiveram a neutralidade e 39\% informaram que perceberam grande interferência estética. Neste caso, a gestão da gruta da Lapinha poderia se valer das diretrizes já consolidadas em âmbito mundial para a gestão de cavernas turísticas (CIGNA; BURRI, 2013), fazendo adaptações estéticas nas infraestruturas que poderiam melhorar este cenário, tais como: substituição gradativa de materiais ou adaptação dos existentes para opções mais integradas à paisagem subterrânea; posicionamento da iluminação; e a regulagem da iluminação para escalas de cores que não interferem no ambiente. 


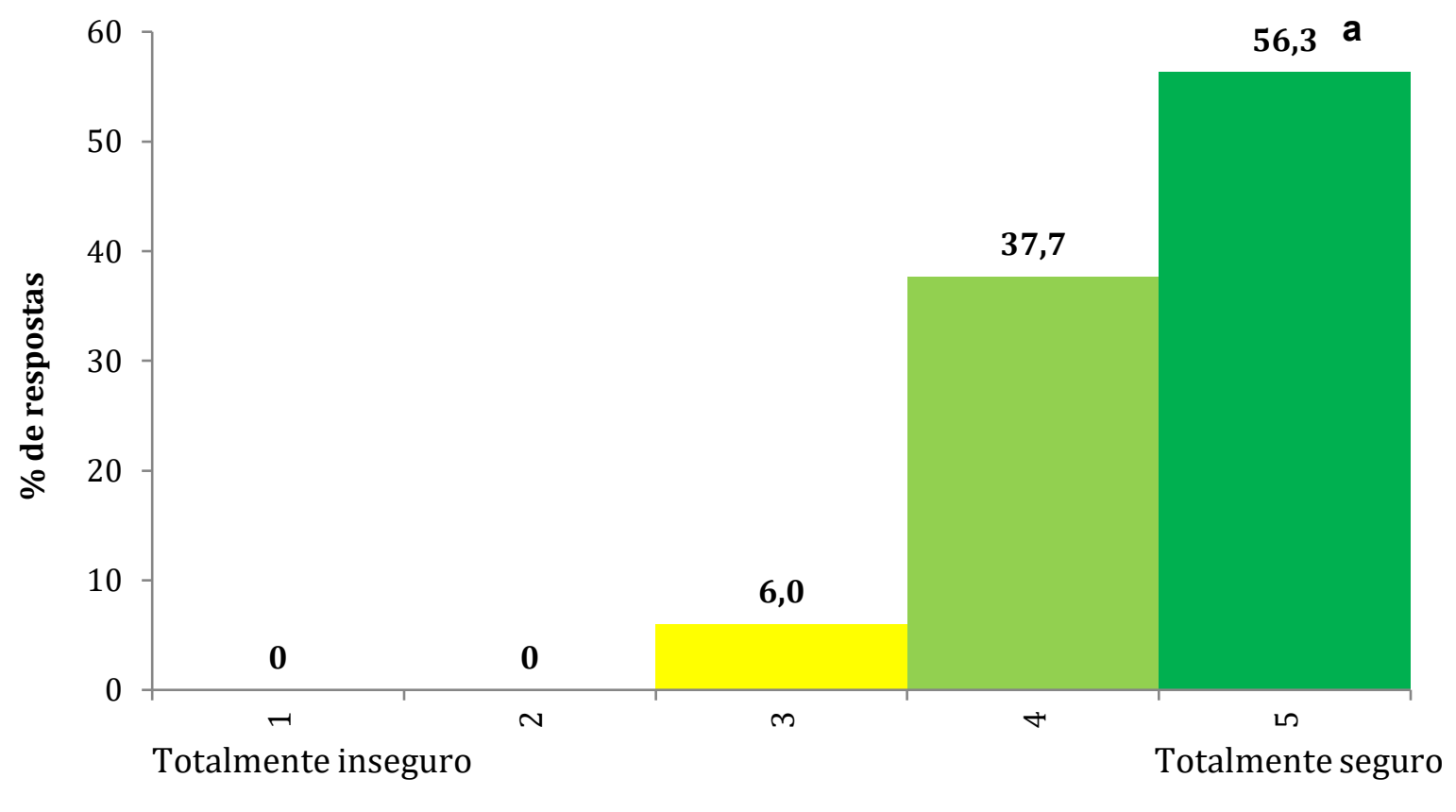

Percepção de segurança da infraestrutura de visitação

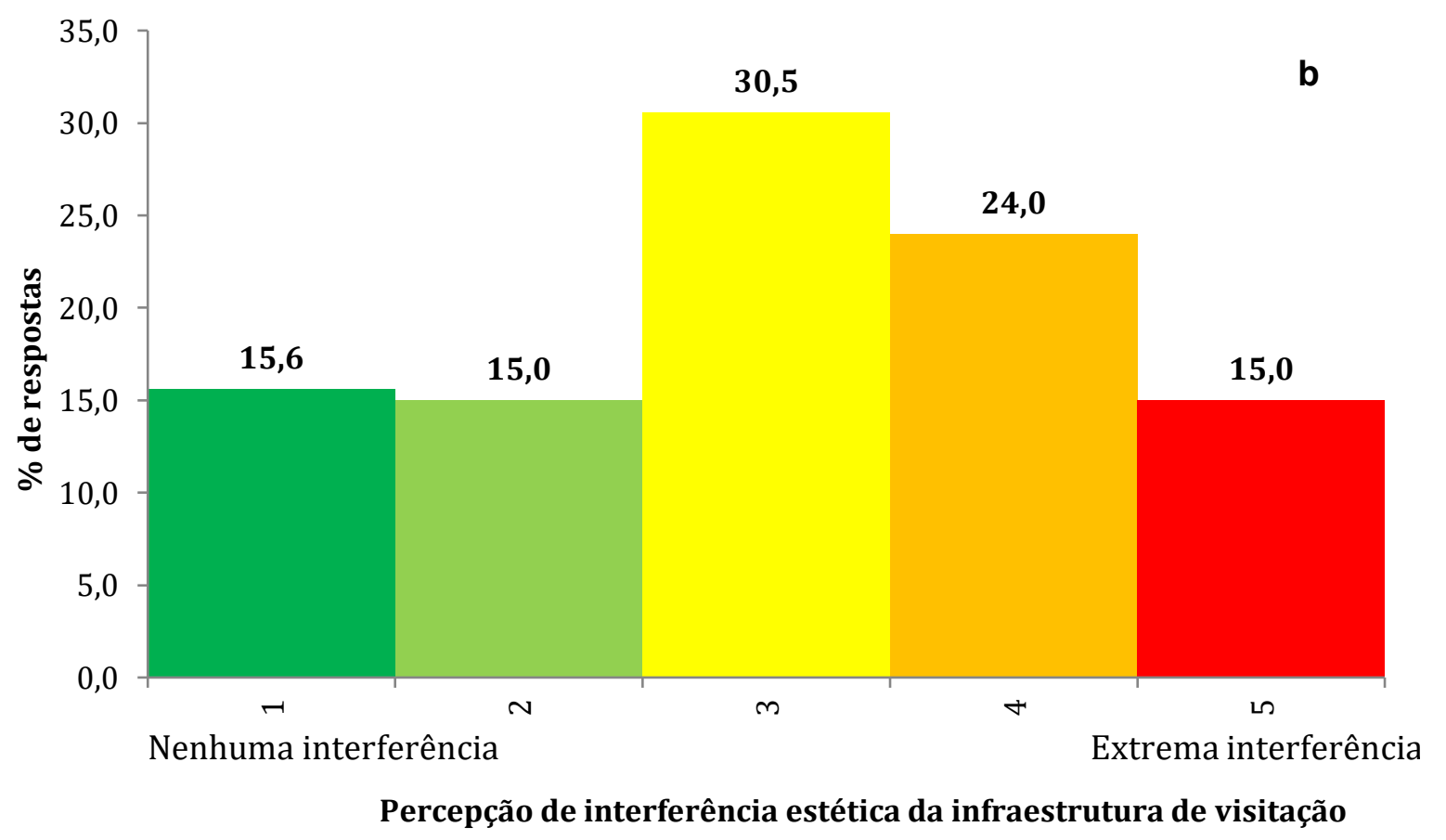

Figura 11. Classificação da segurança (a) e interferência estética (b) da infraestrutura de visitação da gruta da Lapinha 
Para finalizar os aspectos relativos à visitação, pediu-se aos respondentes que avaliassem a sua satisfação geral com a experiência vivenciada (fig.12).

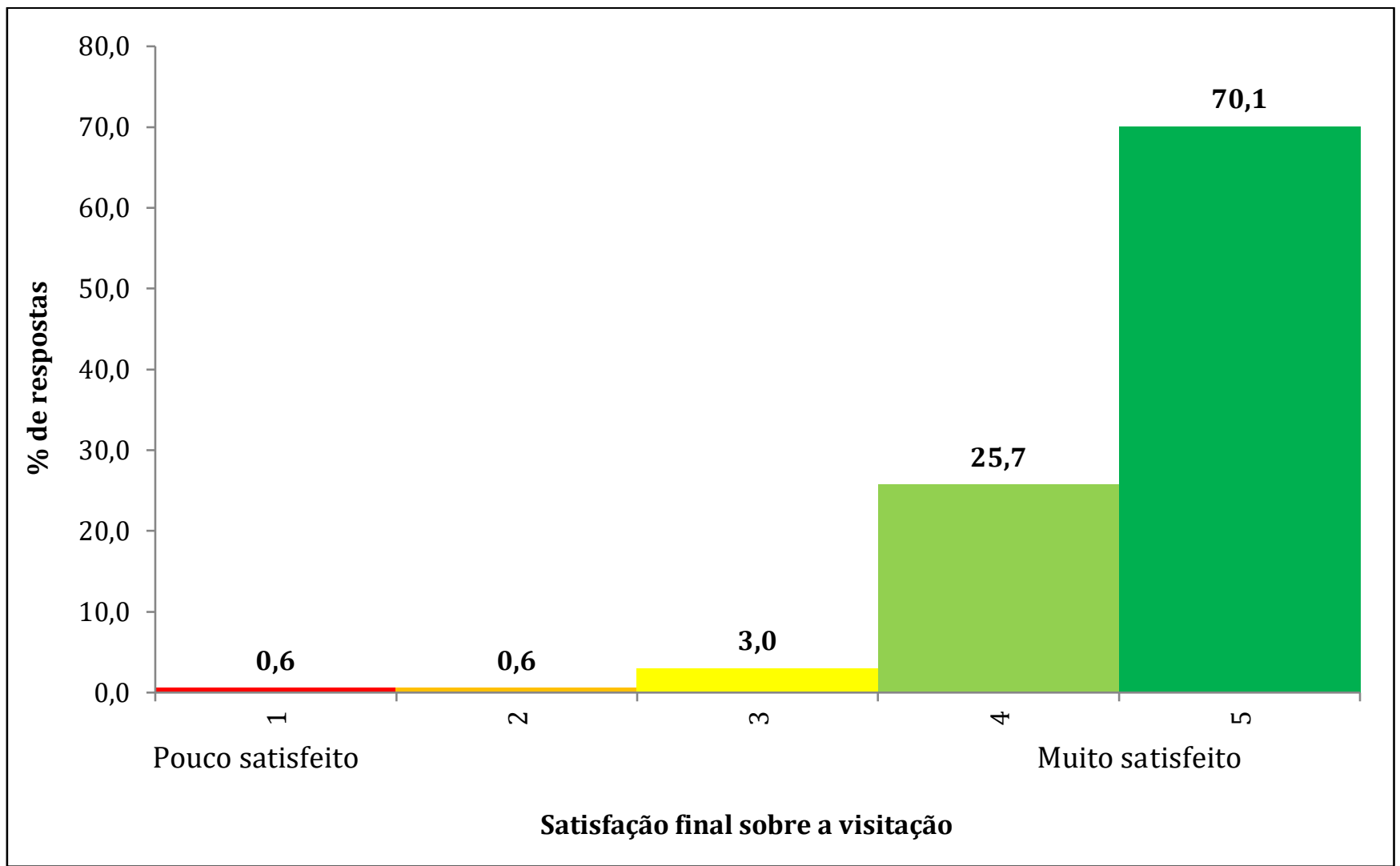

Figura 12. Satisfação quanto a experiência de visitação a gruta da Lapinha

Embora alguns aspectos negativos tenham sido mencionados durante a análise, como o tamanho dos grupos (figs.5 e 6) e a interferência estética das infraestruturas de visitação (fig.11b), a avaliação geral foi bastante positiva (fig.12). As maiores porcentagens de respondentes se concentraram nas opções $4(25,7 \%)$ e $5(70,1 \%)$, o que totaliza $95,8 \%$ de respostas acima do neutro da escala - o qual recebeu apenas 3\% de menções. As anotações negativas foram feitas por apenas 2 respondentes, um em cada opção (1 e 2), de um total de 167 participantes na pesquisa. Esta mesma avaliação predominantemente positiva aparece em relação aos serviços avaliados (fig.13). 


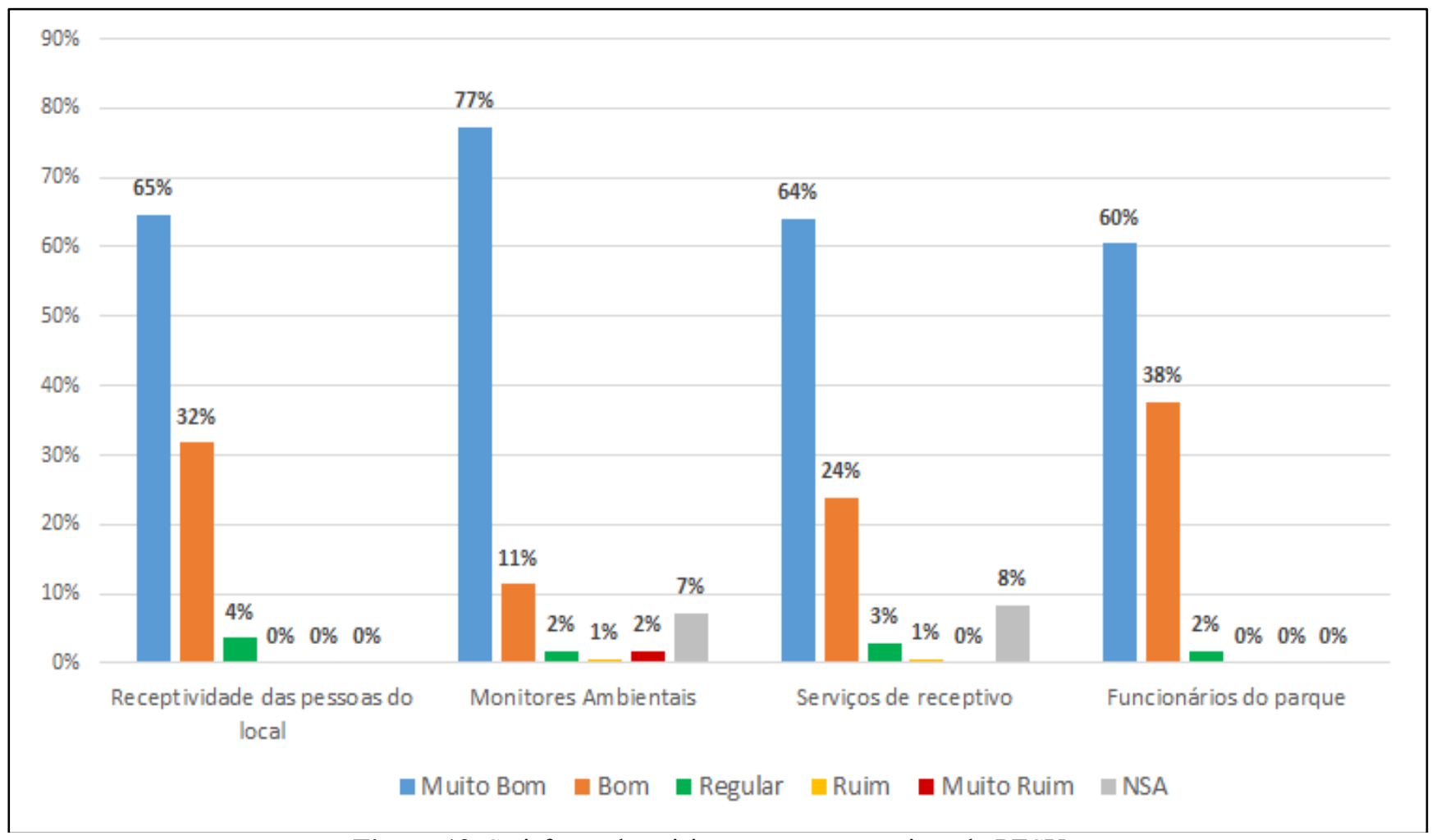

Figura 13. Satisfação dos visitantes com os serviços do PESU

A avaliação geral dos serviços foi positiva para a receptividade das pessoas do local $(65 \%+32 \%$ $=97 \%)$, os monitores ambientais $(77 \%+11 \%=88 \%)$, os serviços de receptivo $(64 \%+24 \%=88 \%)$ e os funcionários do parque $(60 \%+38 \%=98 \%)$. Destes, destaca-se a excelência maior dos monitores ambientais (guias), com $77 \%$ de menções na opção mais alta da escala. Este aspecto deve ser analisado com cuidado, pois não indica, necessariamente, que este serviço é melhor que os demais. Ocorre que, ao passar mais tempo com os visitantes, o monitor tem melhores condições de passar uma boa impressão, se destacando em relação aos outros serviços e funcionários. O mais importante, no entanto, é verificar se os visitantes estão saindo satisfeitos da experiência turística vivenciada (ALEGRE; GARAU, 2010), o que se evidenciou tanto pelas avaliações majoritariamente positivas em quase todos os aspectos avaliados quanto pela avaliação de esforço de deslocamento - 98\% afirmaram que a viagem valeu a pena - e taxa de interesse de retorno - $89 \%$ afirmaram que voltariam a visitar a gruta com certeza e $11 \%$ disseram que talvez voltariam; apenas 1\% assinalaram que não voltariam a visitar a gruta da Lapinha. 


\section{CONCLUSÕES}

A visitação de cavernas turísticas no Brasil é uma atividade que ainda possui amplo potencial de expansão em termos de volume de visitação. O estudo de caso da gruta da Lapinha evidencia esta conclusão, dado que foi notado que mesmo em período de alta temporada, há uma parte significativa do período de visitação em que a caverna fica ociosa. Em termos de perfil de visitantes, observou-se uma demanda heterogênea em seus aspectos sociodemográficos, a qual se posicionou como satisfeita em relação à experiência vivenciada e aos serviços recebidos.

Em relação à percepção de lotação durante a visitação à gruta, uma parcela significativa de visitantes (36,6\%) adentrou a gruta em grupos pequenos (com menos de 15 visitantes), enquanto 11,9\% dos visitantes estavam em grupos com tamanho superior ao permitido. Estas constatações não interferiram de forma linear na percepção de lotação, pois tanto visitantes dos grupos pequenos quanto visitantes dos grupos grandes fizeram apontamentos negativos sobre a sensação de lotação. Fatores pessoais ou mesmo o maior adensamento no momento da visitação podem ser os responsáveis por esta percepção, embora os reais motivos para tal não tenham ficado evidentes.

Quanto aos benefícios do turismo na gruta da Lapinha para as comunidades locais, estes são bastante limitados. Os resultados demonstraram que a população local que não tem relação empregatícia direta com o Parque, não está sendo beneficiada financeiramente com a atividade turística, visto que a maior parte dos visitantes da gruta são excursionistas e, em sua maioria, não se alimentam ou se hospedam no município.

Por fim, ressalta-se que a pesquisa realizada possibilitou identificar diferentes fatores como o perfil do visitante da gruta da Lapinha, grau de satisfação sobre o modelo de visitação atual e o grau de satisfação com os equipamentos e serviços locais. Sobre a percepção de lotação e, por consequência, a capacidade de carga turística, foi possível identificar a necessidade de adequações e ajustes nos limites propostos e sua respectiva gestão, o que pode contribuir para um futuro Plano de Manejo Espeleológico ou programa de gestão do uso público da gruta da Lapinha.

\section{Agradecimentos}

Ao CNPq, pelo financiamento da pesquisa de campo (Processo CNPq n. 455100/2014-4). 


\section{REFERÊNCIAS}

AFONSO, M.H.F.; BORNIA, A.C.; ECHEGARAY, F.; ANDRADE, D.F. Comportamento de consumo sustentável: mensuração com o uso da teoria da resposta ao item. Revista Gestão.Org, v.14, p.16-29, 2016.

ALEGRE, J.; GARAU, J. Tourist satisfaction and dissatisfaction. Annals of Tourism Research, v.37, n.1, p.52-73, 2010.

ALVES, J.V.I. Contribuição dos parâmetros sociais por meio da percepção de lotação e da satisfação do usuário na capacidade de carga turística das cavernas do PETAR (Iporanga-SP). 2016. Trabalho de Conclusão de Curso (Graduação em Turismo) - Universidade Federal de São Carlos.

BARrionuevo, W.; SANTOS, J.A.; CENSONI, J. Cavernas do PETAR - Operação Tatus I. Documentário da TV Educativa do CEPOF - USP - Canal 20. 2019.

BOGGIANI, P.C.; SILVA, O.J.; GESICKI, A.L.D.; GALATI, E.; SALLES, L.O.; LIMA, M.M.E.R. Definição de capacidade de carga turística das cavernas do Monumento Natural Gruta do Lago Azul (Bonito, MS). Geociências, Rio Claro, v.26, n.4, p.333-348, 2007.

BORGES, F. de A.C.; TRAVASSOS, L.E.P.; GUIMARÃES, F.A. Proposta de criação de trilhas geoturísticas no Monumento Natural Estadual Gruta Rei do Mato, Sete Lagoas, Minas Gerais. CLIMEP. Climatologia e Estudos da Paisagem, v.8, p.24-48, 2013.

CALAFORRA, J.M.; FERNÁNDEZ-CORTÉS, A.; SÁNCHEZ-MARTOS, F.; GISBERT, J.; PULIDO$\mathrm{BOSCH}, \mathrm{A}$. Environmental control for determining human impact and permanent visitor capacity in a potential show cave before tourist use. Environmental Conservation, v.30, n.2, p.160-167, 2003.

CAMPO-MARTÍNEZ, S.; GARAU-VADELL, J. B. The generation of tourism destination satisfaction. Tourism Economics, v.16, n.3, p.461-475, 2010.

CIGNA, A.A.; BURRI, E. Development, management and economy of show caves. International Journal of Speleology, v.29, n.1, p.1-27, 2000.

CIGNA, A.A.; FORTI, P. Caves: the most important geoturistic feature in the world. Tourism and Karst Areas, v.6, n.1, p.9-26, 2013.

DOORNE, S. Caves, culture and crowds: carrying capacity meets consumer sovereignty. Journal of Sustainable Tourism, v.8, n.2, p.116-130, 2000.

FEITOSA, A.K.; BARDEN, J.E.; HASAN, C.; KONRAD, O. Hábitos da população no manejo de resíduos sólidos domiciliares: estudo de caso em Juazeiro do Norte - CE. Sustentabilidade em Debate, v.7, p. 212-225, dez/2016 
GRABURN, Nelson H. Secular ritual: a general theory of tourism. In: SMITH, V.; BRENT, M.. Hosts and guests revisited: tourism issues of the 21st century. New York: Cognizant Communication Corporation, 2001. P.42-50.

GUIRADO, E.; GÁZQUEZ, F.; FERNÁNDES-CORTÉS, A.; ARGUMOSA, A.; CALAFORRA, J.M. Cálculo de la visitabilidad máxima en cavidades turísticas mediante el método Cavix: El Soplao (Cantabria). In: CALAFORRA, J.M.; DURÁN, J.J. (Eds). CONGRESO IBEROAMERICANO DE CUEVAS TURISTICAS, I, 2014, Aracena. Anais CUEVATUR 2014. Aracena: ACTIBA, 2014. p.199204.

HEATON, T. Caves: a tremendous range in energy environments on earth. National Speleological Society News, v.8, n.44, p.301-304, 1986.

IEF/MG - INSTITUTO ESTADUAL DE FLORESTAS. Parque Estadual do Sumidouro. Disponível em: $\quad<$ http://www.ief.mg.gov.br/component/content/article/3306-nova-categoria/215-parque-estadualdo-sumidouro $>$. Acesso em: 6.ago.2019.

IEF/MG - InStituto ESTADUAL DE FLORESTAS. GHEOSFERA. Plano de Manejo do Parque Estadual do Sumidouro. Lagoa Santa - Pedro Leopoldo: IEF/GHEOSFERA, 2010.

LOBO, H.A.S. Zoneamento ambiental espeleológico (ZAE): aproximação teórica e delimitação metodológica. Pesquisas em Turismo e Paisagens Cársticas, v.2, n.2, p.113-129, 2009.

LOBO, H.A.S. Tourist carrying capacity of Santana cave (PETAR-SP, Brazil): A new method based on a critical atmospheric parameter. Tourism Management Perspectives, v.16, p.67-75, 2015.

LOBO, H.A.S.; SALLUN FILHO, W.; VERÍSSIMO, C.U.V.; TRAVASSOS, L.E.P.; FIGUEIREDO, L.A.V. de; RASTEIRO, M.A. Espeleoturismo: oferta e demanda em recente expansão e consolidação no Brasil. In: CASTRO, S.F.L. de; SOUTO, W.; RANGEL, B.B. (Coords.) Segmentação do turismo: experiências, tendências e inovações - artigos acadêmicos. Brasília: Ministério do Turismo, 2010. p.35-58.

LOBO, H.A.S.; TRAJANO, E.; MARINHO, M.A.; BICHUETTE, M.E.; SCALEANTE, J.A.B.; SCALEANTE, O.A.F.; ROCHA, B.N.; LATERZA, F.V. Projection of tourist scenarios onto fragility maps: Framework for determination of provisional tourist carrying capacity in a Brazilian show cave. Tourism Management, v.35, p.234-243, 2013.

MACEDO NETO, F.; RIBEIRO, L.C.B. Paleontology. In: SÁNCHEZ, L.E.; LOBO, H.A.S. (Ed.). Guidebook of Good Environmental Practices for the Quarrying of Limestone in Karst Areas. Campinas: Brazilian Speleological Society, 2018. p.164-184.

MANNING, R.E.; HALLO, J.C. The Denaly Park road experience: indicators and standards of quality. Park Science, v.27, n.2, p.33-41, 2010.

MASUTTI, R.F.; LOBO, H.A.S. Análise descritiva do perfil e satisfação dos visitantes da gruta do Lago Azul (Bonito, MS). Entre Lugar, v.9, n.18, p.86-105, 2018. 
McCOOL, S. F.; LIME, D. W. Tourism carrying capacity: tempting fantasy or useful reality? Journal of Sustainable Tourism, v.9, n.5, p.372-388, 2001.

TRAJANO, E.; NERI, A.C. Biodiversity in karst zones. In: SÁNCHEZ, L.E.; LOBO, H.A.S. (Ed.). Guidebook of Good Environmental Practices for the Quarrying of Limestone in Karst Areas. Campinas: Brazilian Speleological Society, 2018. p.127-163.

TRAVASSOS, L.E.P. Assessment of natural and anthropogenic processes in micrometeorology of Postojna cave system by numerical models and modern methods of data acquisition and transfer. Postojna: IZRK/SAZU, 2016. (Research report).

Trabalho enviado em 05/09/2019

Trabalho aceito em $01 / 10 / 2019$ 